\title{
Holism, Particularity, and the Vividness of Life ${ }^{1}$
}

\author{
August Gorman
}

Princeton University

(preprint of article published in The Journal of Ethics 2022, please cite published version here: https://doi.org/10.1007/s10892-022-09394-6)

\section{Introduction}

John Martin Fischer manages to consistently write the kind of philosophy that is exciting, clear, and inspires the reader's further engagement. These virtues are on full display in Death, Immortality, and Meaning in Life. This book in particular is impressive because it manages to provide a masterclass in writing a monograph that is maximally broad in terms of its potential audience while sacrificing little by way of depth. Whether you are an undergraduate, a philosophy of death specialist, or merely an interested layperson, this book provides an engaging invitation to further philosophical reflection on the conditions of our mortality.

While laying out the terrain in many of the major areas of the analytic philosophy of death literature, Fischer articulates original arguments for a number of his own positions, raising ancillary questions ripe for further research along the way. Although the book addresses issues as distinct as whether or not we should fear death any more than we fear anesthesia, whether we should be optimistic about the prospects of uploading our minds to computers, and whether or not philosophical questions would eventually fail to elicit interest in immortal lives (all interesting questions in their own right), I want to focus here on drawing out the underlying axiology that emerges throughout the book when taken as a whole. One particular thread that weaves throughout the book is an inquiry into the way in which we derive various kinds of personal meaning from our experience.

Fischer's view is animated by a strong reverence for life. Despite his disavowal of any form of supernaturalism, he conceives of our world as one in which personal

\footnotetext{
${ }^{1}$ Thanks to Justin Capes, two anonymous referees for the Journal of Ethics, and audience members at the 2021 Pacific APA Book Symposium session for helpful comments that much improved this article. I am truly grateful to John Martin Fischer for his eagerness to engage with my ideas, and the thoughtful and generative way in which he has done so here.
} 
meaning is no less profound or easy to come by. We live in a sort of non-reductive naturalist's heaven on earth, in which our individual experiences could provide us with sources of endless fascination, motivation, and value if only we could live forever to continue to enjoy them. This is a view that I find attractive in many ways, but I am less convinced that we can so easily have our cake and eat it too. As such, my aim in this article will be to test the limits of what I take to be Fischer's commitments and note where they potentially come into tension with each other.

In particular, I'll put pressure on three aspects of his overall view. First, I'll examine whether there might a tension between Fischer's taking meaningfulness in life to be holistic and his commitment to the view that immortal lives would be recognizably human. Next, I'll interrogate Fischer's claim that worries about boredom in immortal lives are predicated on the false view that our pursuits are compelling to us because we value them instrumentally. I'll try to show that this interpretation is incorrect and that it is Fischer who needs to hold a more controversial view of the value of our pursuits. Finally, I will argue that Fischer's seeming acknowledgment that what we get from an experience is sometimes ineffable should make him less skeptical that NearDeath Experiences give the people who undergo them some (defeasible) evidence of the supernatural.

\section{Meaning Holism in Immortal Lives}

While the flavor of radical life extension currently popular among Silicon Valley futurists ${ }^{2}$ focuses on combatting the threat of dying of "natural causes," many of the meatiest conceptual issues concern the desirability of an even more radical kind of immortality - the kind in which one is wholly invulnerable to death and is aware of it. This is because questions about this kind of "true immortality" illuminate the role that the inevitability and/or possibility of death play in structuring our lives.

One of these questions concerns whether or not life without the possibility of death would even be recognizably human. Some think an awareness of death, as Fischer puts it, "'haunts' us, and makes life precious and our various projects urgent; the intense beauty of life, and its capacity for poignancy, stem from our sense of its finitude" (Fischer 2020: 105). Fischer thinks these worries are overblown. Even if limits of some kind are important for supporting a sense of urgency and poignancy, he wonders why in the absence of death there couldn't be plenty of other limits in life to adequately play those roles. The upshot for Fischer, is that immortal life does meet the recognizability condition. He writes, "no question about it: life would be different, if we were

${ }^{2}$ Fischer (2020: 87) interestingly traces this movement back to Francis Bacon, who proposed bizarre antiaging remedies such as wearing red long-johns. 
immortal. But it doesn't follow that it would be so different as to make it unrecognizable as a human life" (Fischer 2020, 108).

Fischer here seems to concede the point that recognizability as a human life is a gradable or threshold notion. This seems right to me. What we desire when we desire body-bound immortality is more human life. So, if there were enough features of immortal life that were not recognizably human we should worry whether or not an immortal life should really be something we should desire since it might not be sufficiently human-like. One factor that might push immortal lives closer to being insufficiently human-like and thus less obviously desirable is the fact that meaningfulness in finite human lives seems to be at least partially holistic.

In Chapter 1, Fischer contends that a crucial part of meaning in life is writing the stories of our lives. I agree that at least for many of us, this kind of first-personal narrative coherence is a very important aspect of our lives. This is one way in which we can see that the value, for us, of any given moment of life might not be able to be captured in isolation, as we need to see clearly the role of that moment in a totalizing explanation, or "an understanding of the whole set of events through the lens of the ending" (Fischer 110). One helpful way of conceiving of this might be as Velleman (2012) describes it: an ending moves us from seeing a life as an open-ended abstraction to a fully specific concrete particular life. The value of our moments are in part a function of the holistic value of our lives. But, given true immortality, our lives would have no endings, so it is unclear whether or not there could even be a coherent whole-life totalizing perspective.

Fischer offers two responses that attempt to make the importance of narrative meaning holism for human lives consistent with the recognizability of immortal lives as recognizably human. First, he floats the possibility that endings are non-essential to narratives. Whatever the truth of that for narratives at large, I think that endings play a very important role in self-narratives as they impact at least one important aspect of practical reasoning. Consider the common advice given to undergraduates that, given the state of the market, they shouldn't go to grad school in philosophy unless they can't imagine doing anything else or else would really enjoy being able to spend 5-10 years reading and writing philosophy without a clear job path in front of them. Part of this advice is about making sure they land on their feet at the end and are able to keep a roof over their head, but even for students who are independently wealthy, this seems like reasonable advice. At least part of the idea, as I take it, is that life is short, so philosophy should really mean something to you if you are going to be spending at least $5-15 \%$ of your life studying it at a high level since it takes such a high level of commitment. But in an immortal life, it wouldn't really matter so much. When our less-than-enthusiastic immortal students would present us with their philosophy grad school aspirations, we might shrug and say, "sure I guess, as long as you have a plan to make sure you'll end up on your feet financially." If it's a disaster, its significance 
for their larger life story will almost certainly fade over time. This certainly seems to me like a loss of both the urgency and poignancy of at least many of our choices.

Now some might respond: well, so much for our ordinary practical reasoning! While this feature of immortal life might not be humanlike, it is even better: super-humanlike! Since it differs only in that it opens up more good possibilities and the chance to wash away our mistakes against the horizon of forever, there's no reason to find it any less desirable! While there is admittedly something attractive about the opportunity to try out a wider variety of pursuits with less stress, I worry that without the constraint of death on our life stories we would be subject to significant difficulties with motivation. Imagine, if you will, the following conversation between two immortal lovers:

IMMORTAL LOVER 1: All I'm asking you to do is to commit to being with me for the rest of time.

IMMORTAL LOVER 2: I fully intend to commit to you, but I just don't understand why you're rushing me and I can't spend 2,000 years doing something else first. IMMORTAL LOVER 1: Call me greedy if you want, or just head-over-heels in love, but I want as long of a period of time to spend with you as possible!

IMMORTAL LOVER 2: How many times do I have to tell you? Whether I commit to you now, one year from now, or 2,000 years from now, we will have the exact same amount of time to spend together: $\aleph_{0}$ years!

IMMORTAL LOVER 1: I feel like every 2,000 years when I ask for your commitment you always say the same thing...

While it's easy to get the sense that Immortal Lover 2 is pulling one over on Immortal Lover 1, Immortal Lover 2 is, as far as I can see, correct. What reason do they have for committing now when they could spend the same amount of time together after waiting another 2,000 years? ${ }^{3}$ Similar motivational problems could arise even in simple cases, where, for example, you want to make enough money to spend twenty years in retirement on painting. In an immortal life, it doesn't matter how long it takes you to make the money, there will always be twenty years left to devote to painting, undercutting at least some part of what ordinarily motivates us. Perhaps we would adapt to reason quite differently in the scenario in which we all have true immortality, but I think it should be admitted that this kind of practical reasoning (especially about decisions to spend infinite amounts of time on something) would be very strange indeed, and quite foreign to the experience of human life as we currently know it.

\footnotetext{
${ }^{3}$ One wrinkle here, which only serves to increase the foreignness of immortal reasoning, is that once the lovers do commit to one another for some finite amount of time it would be correct to say at any given time that they could have had the previous 2,000 years prior together as well, which they in some sense "missed out on." But once the fact that they will be together forever is brought into view, Immortal Lover 2 can make the case that the order does not matter since the years they "missed out on" make no difference to the total number of years they'll spend together.
} 
Think back again to the advice given to aspiring grad students. Some might object that I am wrongly assuming there is some important expressive significance that comes from the proportion of one's life one plans to spend on a particular pursuit, when really the expressive significance comes from the absolute amount of time one spends on a pursuit. As we've seen, the expressive significance of spending an absolute amount of time on something gets very strange in the case of spending infinite amounts of time on life-projects. But at least in life-projects that are pursued over finite lengths of time this might be seen as a prima facie plausible hypothesis about expressive significance for one's life story.

I take it that an important part of writing the stories of our lives is aiming to end up with the kind of life that we would be most satisfied with, if we were to look back at the end of it all, and for many of us a relevant feature to our degree of satisfaction is the narrative that holds all of the events together. ${ }^{4}$ The problem in infinite lives, though, is that there would be no fixity of how significant a particular period of time or episode would be held to be in the grand scheme of one's life. At any time, you could decide last minute to take a two-hundred year project, zoom out your perspective on your life-narrative, and treat it as merely a footnote. The fact that nothing prevents you from doing this at any time you like keeps the significance of your pursuits forever malleable in a way that they are not in finite life. This seems to me to be significantly different from the way in which our finite self-narratives affect our choices.

This is not to say that there couldn't be any constraints on practical reasoning in immortal lives, as situational factors will often affect choices. After all, Immortal Lover 2 may be influenced in their choice of when to commit by the desire to kiss Immortal Lover 1 when her hair is reflecting the moonlight just so-an opportunity that may come about just once across the expanse of eternity. But insofar as our significant life choices are influenced by choices about the expressive meaning of the duration of our commitments, we ought to worry that immortality would threaten an important kind of exercise of autonomy, bringing along with it downstream effects on our everyday motivation.

Fischer offers a really intriguing second suggestion that might help respond to these sorts of worries I've posed, though. We could, he suggests, think of our immortal lives as corresponding to a series of novels with the same protagonist, thus imposing our own set of "endings" onto our lives (Fischer 2020: 110-111). Ben Mitchell-Yellin (2021: 134) has similarly argued recently that infinite lives might be best conceived of as soap-operas: episodic but indefinite. It does seem to me that this might be an important way to try to conceptualize our lives if we were immortal in order to be able

\footnotetext{
${ }^{4}$ I take this to be independently plausible, but my view here of the relevance of self-narrative to practical reasoning is inspired by and meant to be compatible with a view of prudence that links what one ought to do with what would contribute the most to one's life overall, such as the view first articulated in (Bricker 1980). I provide a partial defense of this view in (Gorman 2021).
} 
to think. (This insight also helps remind us that even in our mortal lives many of our narratives are short-lived and come to their own natural endings; we cycle through seasons of emotional build-up and release that are satisfying even as chapters that could be reprinted absent of their greater context within our lives taken as a whole.) Nevertheless, I want to draw out a few features of just how different it would be if we were to attempt to replace our reasoning that does involve taking a totalizing view of our lives by artificially setting endings. Taken together, I think these considerations cast doubt on the degree to which making use of such endings contributes to living a life that is still recognizably human:

1. In mortal life the ending is uncertain, which inspires an extra sense of urgency. While "live each day as if it's your last" is not good advice when not counterbalanced by a consideration of the value of long-term planning, there does seem to be something to the idea. Imposing an artificial sense of an ending on your life can't get you this same sense of uncertainty.

2. Imposing a particular ending on yourself is at least somewhat arbitrary, such that it seems that while living out one of the narratives, the ending day would always be negotiable. Perhaps the value of endings could play some role in getting you to commit to treating a particular day as the ending. That said, it's not clear that the pragmatic value of having these kinds of commitments to treating certain days as endings could serve to ensure actual commitment to treating a particular day as an ending. Even Michael Bratman, a leading proponent of the importance of commitment in normal agential functioning holds that agents are able to override or change their commitments when they are not satisfied with them (Bratman 1996).

3. This entire process of conceptualizing one's life in terms of a series of novels with endings would require a significantly higher degree of meta-cognition than the process by which we implicitly shape our mortal lives in response to narrative considerations. We are able to reflect on our mortal lives from the perspective of thinking about self-narratives and aiming towards fitting endings, but it would be quite a different thing to have to reflect and intentionally introduce these elements of conceptual framing in order to reap the same benefits.

4. Without social coordination, people would choose different ending points for their stories from one another which could present a number of practical conflicts. Relatedly, in mortal life there are shared social meanings already at hand for life stories, but in an immortal life the shape that the chosen beginnings and ends of each life "novel" give to the series would have to be explicitly declared or explained without imposed social cohesion.

I don't want to deny that it's quite possible that ingenious cultural solutions would arise in an immortal society to meet these practical challenges; I am not a full-blown 
Immortality Curmudgeon and I retain some sense of hope that an immortal life could be desirable for people with specific sorts of constitutions in certain ideal circumstances (Gorman 2019/ 2020). But I think that either Fischer's optimism that life would still be recognizably human in all the ways that really matter ought to be significantly tempered, or else we have to concede the relevance of meaning holism for the humanness of life.

\section{Boredom and the Particularity of Experience}

After attempting to establish the relative humanness of the life of the true immortal, Fischer turns his attention to the more traditional debate, sparked by Bernard Williams, about whether or not immortal life would eventually invariably become intolerably boring. Williams' argument has been a source of much discussion in part, because it promises to offer a salve to our despair over the fact of our own mortality. (See Williams (1973) for the initial presentation of the argument. See Gorman (2016) for a canvassing of contemporary interpretations of the argument.) If Williams is right, then even when our deaths are tragic, the fact that we must die at some point is a blessing in disguise since we avoid having to continue living after we have exhausted all there is for us to live for.

Fischer has long expressed significant skepticism about this position, challenging Williams-inspired Immortality Curmudgeons to articulate just what would be so different about living forever that would differentiate it from our normal mortal lives in which we are sometimes bored but find new things to do, re-engage old interests, find continued pleasure in repeated pleasurable experiences, and seemingly manage to continue on just fine.

Here Fischer takes a new angle on criticizing the Curmudgeon position, accusing the Curmudgeon of misunderstanding the process of obtaining value from our experiences. The Curmudgeon mistakenly thinks both that the value is such that obtaining it is tantamount to extracting it, and that we are only interested in pursuing value that is suitably distinct from the value we have already extracted from other experiences. In previous work Fischer has made a case for living for the existence of pure bodily pleasures which needn't be as lofty as the life projects Curmudgeons worry would get exhausted in immortal life (Fischer 1994: Fischer and Mitchell-Yellin 2014). Everything he says here is compatible with that view. But the argument he puts forward in this book seems to me to be interestingly different since he now accuses the Curmudgeons of being overly reductionistic about the value of certain projects and pursuits.

The crux here is a disagreement between Fischer and Shelly Kagan. Kagan writes of his immortal self, "I've seen thousands, millions, billions of incredible works of art. I've gotten what there is to get of them. Isn't there anything new? And the problem is that there isn't" (Kagan 2012: 243/ Fischer 2020: 127). Fischer finds Kagan's reaction 
here hard to understand, and implies that this is an overly-reductive way of understanding the experience of appreciating art. "Getting all there is to have gotten out of" something might make sense when talking about something instrumentally valuable, like, say, an SAT prep book. But Fischer claims that it is the wrong way to think about pursuits where "the experience itself can be valuable and compelling" like appreciating art, doing high-level math or philosophy, pursuing friendship or love, or having sex (Fischer 2020: 128-129). There is no reason to think, Fischer says, that any of these sorts of activities (if suitably integrated into a balanced life without too much of any one kind of activity) couldn't provide a reliably repeatable source of value in an immortal life. Although he doesn't develop the point here, Fischer might also hold that there are, in theory, an infinite number of experiences a person could have that share this quality of being both valuable and compelling in and of themselves. ${ }^{5}$

Let's return to Kagan's art appreciation example. The first question we might ask is why Kagan thinks you can't just go see the same works of art again. Fischer's diagnosis is that Kagan thinks of the experience of a work of art as merely instrumentally valuable, perhaps providing some sort of information or insight (Fischer 2020: 128). I think Fischer is wrong that the intrinsic/instrumental distinction is the right way to think about this dispute. It might be that someone "gets what there is to get out of" an experience that is intrinsically valuable. For example, I value certain childhood relationships and experiences I had. I value them in part for instrumental reasons-because of the lessons they taught me-but I also just intrinsically value those experiences. Nevertheless, it's also true that I've already gotten what there is to get out of them for me; I wouldn't want to live forever repeating them.

My suspicion is that Fischer is actually implicitly committed to something more controversial about the nature of the value of experience. He wants to claim that the experience of appreciating a work of art could be not only valuable but compelling, in theory, in a non-extractable, non-exhaustible way. Since appreciating art arguably involves taking an interest in the art and not just passively experiencing the pleasure of swirls of color, this seems to imply that if you were in the right mindset and circumstances, experiencing a particular work of art could provide you with an infinite source of interest. And this source of interest, as we've seen, would have to be such that it's not possible for you to (wholly) articulate it in terms of insights gleaned. What might this look like? Perhaps the value is in the particularity of the experience.

Fischer's comments about friendship and love support this reading as well. He says that friendship and love are full of "magic" and "mystery" and have "irreducible

\footnotetext{
${ }^{5}$ Note that Kagan has worried about, but not established that for a given individual there are only a finite number of factors or combinations that are capable of "engaging them afresh." Kagan could be wrong about this while being right that these qualities of art appreciation are individually exhaustible. This is a different point than the one about reliably repeatable engagement with the same qualities multiple times. These assumptions about whether the different possibilities that exist for experience are infinite are difficult to argue for or against and, perhaps, partially explain the stalemate in this debate.
} 
experiential features" (Fischer 2020: 129). He takes issue with the idea that someone might take what we might call a "Gotta Catch 'Em All" attitude towards friendship, seeing your pursuit as consistent with checking off a list all of the interestingly different kinds of friends there are to have. ${ }^{6}$ The value of a particular relationship with a particular person is often thought to be the most compelling example of value that is in this sense, particularist-we like people not just because of the good qualities they possess but because we like the fact that everything about them is just so. The experiences that Fischer thinks would sustain us in an immortal life might be related to the kinds of experiences that Fischer, in Chapter 1, tells us lend life its "rich texture." In Chapter 1, Fischer writes that zooming out too far in our perspective on life "makes it impossible to see the rich texture of our lives, including its particularity." He quotes the following passage from Kate Bowler:

...there is nothing generic about human life....There is no life in general. Each day has been a collection of trivial details - little intimacies and jokes and screw-ups and realizations. My problems can't be solved by...formulas...God may be universal, but I am not. I am Toban's wife and Zach's mom and Karen and Gerry's daughter. I am here now, bolted in time and place, to the busy sounds of a blond boy in dinosaur pajamas crashing into every piece of furniture (Bowler 2018: 124145/ Fischer 2020: 19).

Notice here the role that pointing to particular relationships plays in expressing the value of the particularity of the experience of the moment.

I suspect that particularism about the value of experiences is also at the crux of the fact that Fischer and Kagan disagree about whether or not there will always be more art available to appreciate that will provide for suitably distinct experiences from the experiences of appreciating all the previous works of art. Consider a teacher who gives her beginning photography students a list of kinds of photographs to take over the course of the semester: a photograph that captures motion, a close-up photograph with a macro lens, a photograph from an unusual perspective, a photograph without color, a candid photograph of a person, etc. For Kagan, there is a list like this that describes ways art can be, and what is valuable about art are these aspects, or perhaps there is value in many different combinations of aspects. The list of aspects is very long, but there is a list and it is finite. The possibilities for the combination of different aspects is exceedingly long, but still within the realm of finitary combinatorics. These aspects needn't be valuable only because the produce some sort of cognitive by-products but might be valuable because they produce a certain kind of experience. ${ }^{7}$

\footnotetext{
${ }^{6}$ Lest this reference be lost to the sands of time, "Gotta Catch 'Em All" is the tagline and theme-song for the 1995 media franchise Pokémon.

${ }^{7}$ Since art appreciation surely involves the "eye of the beholder" even if not fully contained within it, we might look also towards possible differences in us as perceivers over time that can have a bearing on how we come
} 
If I'm right about how Fischer is thinking about the value of experience, I would predict that he, unlike Kagan, would think that you cannot, even in theory, predict ahead of time any rules about which photographs will end up being especially valuable to you off of the combination of aspects they will embody. As long as there is an infinite number of photographs that could exist, there could always be interestingly new works of photography to appreciate. This is because the value of each photograph is particular and not composed of the value of its aspects. As a way to test this theory, I'd be curious to ask both Fischer and Shelly Kagan whether or not they think there could ever be a programmable algorithm that could predict with $100 \%$ accuracy whether or not someone would like a photograph before they ever see it. I would expect Fischer to say "no" and Kagan to say "yes."

This kind of particularism is a position well-worth exploring, but I do think that it requires argument. If I am off the mark here, I would challenge Fischer to further explain why he thinks it would be reductionistic to think that many intrinsically valuable experiences are exhaustible and that we would get intolerably bored after running through a list, billions long, of interestingly different kinds of art to appreciate or friendships to pursue.

\section{$4 \quad$ Vividness and Supernaturalism}

Finally, I want to turn from the properties of experience that sustain our interest and give our lives meaning, to their epistemic value. In particular, in this section my focus will be on the epistemic value of so-called Near-Death Experiences, in which a person having a life-jeopardizing medical event loses consciousness, and reports a fantastical experience of some sort. Prototypically, the person sees a tunnel and is guided to a light at the end of it by her deceased loved ones, watches her body being operated on from above, and then feels like she is returning into her body. Over the course of several chapters of Death, Immortality, and Meaning in Life, Fischer builds the case that the arguments presented in popular books that aim to show that some Near-Death Experience of this kind or another can provide us with irrefutable proof of the existence of a supernatural realm fall short. While few philosophers would find much to disagree with here, what might be more controversial is the naturalism-friendly alternative explanation of the profound effect of these experiences that Fischer offers (see also,

to perceive the work of art such that it is not so easy to get all that there is to get out of a particular experience. For discussion, see (Fischer and Mitchell-Yellin 2014). Kagan, perhaps, might think we could make a long but finite list of any such effects that would have a relevant and significant effect on our appreciation for a certain work of art. This would mean that revisiting old works of could be a worthwhile pursuit for a longer period of time before one would run into the limits of its value. It's conceptually possible that there are infinite qualities of a perceiver that can combine with finite combinable aspects of artworks such that engaging with art is repeatably worthwhile infinitely on the basis of this variation alone, but this would be a somewhat surprising conclusion. 
Fischer and Mitchell-Yellin 2016). Fischer diagnoses that authors of these popular books tend to equivocate between using the word "real" to mean that their experiences really happened to them and using it to mean that the contents of their experiences were veridical, because they get caught up in responding understandably forcefully to people who make them feel crazy by saying that their experiences weren't real. As Fischer wants to emphasize, it is entirely possible that authors like neurosurgeon Eben Alexander's experience really did happen, and in many cases these experiences inspired real change for the person that shouldn't be trivialized.

As much as I agree with the general thrust of Fischer's arguments in these chapters and appreciate the newfound clarity they might offer someone wading into the NearDeath Experiences literature, I want to point out a couple of places in which I think Fischer might overstate the argumentative conclusions he is warranted in making, given both the concessions he makes to people who find these experiences meaningful and the value he places on direct experience elsewhere in the book. Fischer takes the position that there is really no good reason to think that having a Near-Death Experience is evidence of the supernatural. I want to at least explore the view that while it is true that the arguments that people who experience Near-Death Experiences make shouldn't convince others that there is a supernatural realm, they might provide some weak defeasible reasons to believe in the supernatural for the people who directly experience them. I am, at least, less sure that Fischer has provided an argument against those kinds of Near-Death religious converts that he can square with his other commitments.

To see what I mean, imagine someone who goes through a Near-Death Experience of the prototypical kind who believes that her experience was veridical, and it sparks a newfound belief for her in a supernatural realm. But unlike how Fischer imagines his interlocutors who have undergone Near-Death Experiences, her belief in the supernatural does not come about because she thinks that a supernatural realm is the best explanation of how a person situated as she was could have come to have the experiences of seeing a tunnel, being guided to a light, etc. Instead, it is the fact that her concurrent awareness of what her experiences were like indicated to her that there was something special about them that gave her reason to believe they were supernatural. This might sound somewhat obscure, but consider the felt experiential aspects of conscious wakeful experience that most of us rely on to tell us that we' re not dreaming. Let's call this "vividness," although perhaps it really has something more to do with a greater degree of awareness or coherence. Perhaps the difference between the kind of consciousness experienced in the Near-Death Experiences and regular waking consciousness can be put in analogy with the difference between regular waking consciousness and dreaming experience.

I'm not sure if that's what these experiences are like, as I've never had one myself, but I do wonder if something like that might be what Eben Alexander really means 
when he repeatedly refers to his experience as "ultra-real" (Fischer 2020: 148). Fischer also cites some reports that indicate that there is frequently supernormal vision associated with Near-Death Experiences (Fischer 2020: 161). If people are really able to, for example, see colors that humans aren't ordinarily able to see during these experiences, this seems pretty similar to some of the tests people think give them evidence that they're awake rather than dreaming-for example, some people claim that they can tell they're not dreaming because they have the extra mental capacity to read a book, which they cannot do in their dreams. Heightened mental and sensory capacities, as well as a metacognitive sense that we could utilize such capacities if we wanted to are part of what seem to suggest to people that they're in a more "real" state of consciousness. Just as being awake is considered to be more real than dreaming, perhaps those who convert after a Near-Death Experience use the language of the supernatural to describe the fact that they believe they have experienced something different in kind and more real than ordinary wakeful consciousness, and thus, certainly more real than dreaming.

If something like that is right, I'm not so sure that Fischer has provided an argument that the people who have these experiences shouldn't take them seriously as some evidence of supernaturalism, even if it's not shareable in the form of an argument they can give others for the existence of supernaturalism. Fischer argues that the vividness of Near-Death Experiences doesn't support a non-physicalist interpretation of them (Fischer 2020: 160-162). He argues that dreams, hallucinations, and virtual reality can be especially "vivid" but that doesn't warrant reaching for a non-physicalist interpretation. But I worry that Fischer misunderstands the kind of vividness experienced in Near-Death Experiences. It's not just eating extra-juicy apples or seeing sunsets that are extra beautiful, it's the experience of what it's like to be (for lack of a better term) 'conscious' as an experiencing agent that seems to somehow be described as different in kind.

Now, I don't want to overstate my criticism here. Arguably, there are better ways of telling that you are not dreaming than by reflecting on the nature of what the experience of being conscious in the present moment is like-perhaps there is some knockdown argument in the literature against dreaming skepticism. (See Windt [2019] for an overview of dreaming skepticism in epistemology). But for most people the ongoing felt qualities of the experience of being awake rather than dreaming seem to suffice as some sort of assurance. At the very least, even if someone presented you with some argument that aimed to prove that, contrary to what you believe, you were dreaming right now, the experiential qualities of your experience that are indicating to you that you are not, even if you can't quite articulate them, would be reasonable to take into consideration. I can see why people who have Near-Death Experiences would be averse to hearing that they have no good reasons to believe that they aren't something much more akin to dreams. Given that they are experienced as being more real than 
ordinary reality and they occur when one is near death, is it really that unreasonable to think that a good explanation is that there is some realm after death?

Fischer thinks it is unreasonable. While, as he notes, there is no adequate neurophysiological explanation of Near-Death Experiences, we should have faith that such an explanation will be developed in the future since neurophysiology is in its infancy. As he puts it,

It is totally unreasonable to give up on a physical explanation of the brain processes that underlie NDEs just because we don't have one now. It is better to bet on science in this matter. What is more sensible: to believe that eventually science will generate an adequate understanding of the neurophysiology underlying NDEs, or that the mind is nonphysical and grasps facts about the physical and supernatural realms via nonphysical means (Fischer 2020: 154)?

Of course I see the appeal of the naturalistic project and the hope of being able to get everything to fit within its paradigm, but I think Fischer's faith in science here might be a bit inflated. Even if we were able to identify some physical processes, there would remain a question of whether or not they provide the whole story, as it were. Fischer mentions the astonishing likeness to the NDE experience that some people have while under the influence of hallucinogenic drugs like LSD, which seems to suggest that the most we might say about these kinds of experiences is that they are the result of odd (physical) things happening to the brain. But, as he acknowledges, despite the fact that the cause of the LSD-induced experience is indisputably physical, this is not yet an argument that the richness of such experiences will be wholly describable in physical terms, as countless faiths have seen such drugs as tools for better attuning oneself to perceptions of the supernatural realm.

Rather than entertain the possibility that these perceptions are veridical, Fischer seems to think that a better explanation is that future neuropsychological findings will tell the whole story, as it were, but that there is also an important affective mode of appreciating these same non-supernatural experiences. In order to vindicate the idea that Near-Death Experiences can be genuinely profound in a distinctive way, Fischer points towards the nature of the aesthetic realm. This is intriguing, since particular experiences of beauty are just the sorts of things that have historically pushed people away from the idea that we can get a scientific picture of reality that fully captures everything. ${ }^{8}$ Fischer, instead, wants to say that the profundity of a Near-Death Experience comes from an emotional way of understanding a physically-describable experience. As he puts it,

\footnotetext{
${ }^{8}$ Why think this? One reason might be the fact that the scientific picture of reality is arguably meant to show how everything is governed by lawlike processes. But ordinary aesthetic thought gives us good reasons to embrace both that aesthetic properties are anomalous (that is, there don't seem to be laws governing the correctness of aesthetic judgments), mind-independent, and supervene on nonaesthetic properties. See (Zangwill 2019) for discussion of this suite of unusual features that aesthetic properties seem to have.
} 
It is important that my claim is not simply that NDEs help us to see the point about solidarity and love. They do not just issue in a new piece of information. Rather, the stories they tell give us an emotional understanding of this point. They get us to see it via a story, and thus we do not just have cognitive understanding, but an affective grasp of the insight. It is a deeper kind of understanding, one that combines intellectual with the emotional-explanation and storytelling (Fischer 2020: 180).

I would be curious to hear more about how Fischer wants to square this picture of needing an affective mode of understanding to appreciate the profundity of an experience with his non-reductive naturalistic project. In particular, how should we think about the fact that the affective mode seems to respond to the particular while the scientific mode is able to describe generalizable truths? Are the very same properties of experience being described in two different ways, or are there different qualities of the very same experience which have different fineness of grain?

If people who experience Near-Death Experiences really do have a deeper kind of understanding of their experiences than neuropsychologists could, why couldn't their experience provide some defeasible epistemic insight into the nature of what's going on? If I am right about the fact that elsewhere in the book Fischer endorses the view that the particular and ineffable can provide meaningfulness value which can't be easily shared with others, why couldn't the particular and ineffable also provide epistemic value which can't easily be shared others?

\section{Conclusion}

I have argued that we ought to temper our enthusiasm towards Fischer's vision of immortal life, and, at least for the time being, remain cautious towards the prospect of drinking an elixir of eternal life on Earth. For one thing, there is a fundamental tension between the plausible view that meaningfulness in life is holistic and the prospect that lives that lack genuine endings would be fundamentally human-like. Additionally, boredom remains a real threat for immortal lives, even if many of our experiences are intrinsically valuable.

Furthermore, a naturalistic reinterpretation of Near-Death Experiences might leave us with more questions than it answers. If people who experience Near-Death Experiences experience something different from waking life in analogy to the way that waking life feels different from dreaming, it might not be unreasonable for them to take themselves to have first-personal (defeasible) evidence of the supernatural.

In the final chapter of the book, (fittingly and humorously titled "The Final Chapter"), Fischer worries that the middle-ground paths he takes throughout the book might "seem like a bowl of mushy metaphysical oatmeal" (Fischer 2020: 188). But, he 
tells us, there is often wisdom in the Middle Way, and he hopes that his attempt to find it will "crystallize the wisdom of opposing sides without the excess baggage of each" (Fischer 2020: 188). It is these attributes of Fischer's picture that make it so compelling, and worth pursuing. At the end of the day, though, it seems as though the world that naturalism describes might be one that most of us should only want to live in for a limited time, and naturalist conceptions of our world stop short of being able to explain particular experiential contact with the sublime. If we want to seek heaven, we might still need to look upwards.

\section{References}

Alexander, Eben. 2012. Proof of heaven: A neurosurgeon's journey into the afterlife. New York: Simon and Schuster.

Bowler, Kate. 2008. Everything happens for a reason and other lies I have loved. New York: Random House.

Bratman, Michael. 1996. Identification, decision, and treating as a reason. Philosophical Topics 24(2): 1-18.

Bricker, Phillip. 1980. Prudence. Journal of Philosophy 77 (7): 381-401.

Fischer, John Martin. 2020. Death, immortality, and meaning in life. New York: Oxford University Press.

Fischer, John Martin. 1994. Why immortality is not so bad. International Journal of Philosophical Studies 2(2): 257-270.

Fischer, John and Mitchell-Yellin, Benjamin. 2016. Near-Death Experiences: Understanding visions of the afterlife. New York: Oxford University Press.

Fischer, John Martin \& Mitchell-Yellin, Benjamin. 2014. Immortality and boredom. The Journal of Ethics 18(4): 353-372. 
Gorman, A. G. 2017. Williams and the desirability of body-bound immortality revisited. European Journal of Philosophy 25(4): 1062-1083.

Gorman, August 2020. Taking stock of the risks of life without death. In Exploring the philosophy of death and dying: Classical and contemporary perspectives, eds. Michael Cholbi and Travis Timmerman 137-143. Abington: Routledge.

Gorman, August 2021. Living your best life. Analysis. 81(3): 568-576.

Kagan, Shelly. 2012. Death. New Haven, CT: Yale University Press.

Mitchell-Yellin, Benjamin. 2021. How to live a never-ending novela: (or, why immortality needn't undermine identity). In Exploring the philosophy of death and dying: Classical and contemporary perspectives, 131-136. eds. Michael Cholbi and Travis Timmerman. Abington: Routledge.

Velleman, J. David. 2012. Dying. Think 11(32): 29-32.

Williams, Bernard. 1973. The Makropoulos Case: Reflections on the tedium of immortality. Problems of the Self: Philosophical Papers 1956-1972. Cambridge: Cambridge University Press.

Windt, Jennifer M. 2019. Dreams and dreaming. The Stanford Encyclopedia of Philosophy (Summer 2021 Edition), ed. Edward N. Zalta https://plato.stanford.edu/archives/sum2021/entries/dreams-dreaming/

Zangwill, Nick. 2019. Aesthetic judgment. The Stanford Encyclopedia of Philosophy (Summer 2021 Edition), ed. Edward N. Zalta https://plato.stanford.edu/archives/spr2021/entries/aesthetic-judgment/ 